\title{
Barriers To The Use Of Information And Communication Technologies In Teaching And Learning Business Education
}

Titus A. Umoru, Ph.D., Kwara State University, Nigeria

\begin{abstract}
Education is an instrument "per excellence" for national development. Business education is one of the programs run in about 117 universities in Nigeria. It was believed that business education has the capacity to bring about the required development since it is a course of instruction aimed at inculcating in the youth the skills, attitudes and competencies which are necessary to empower them to be gainfully engaged so that they will be useful citizens and contribute to the development of Nigeria and the society. However, there seemed to be gaps between the nation's educational objectives and their realization. The obvious indicators to this fact are poor skills of graduates who cannot fit into the office of today, unemployment, poverty and underdevelopment of the country. Information and Communication Technologies (ICTs) where properly utilized is capable of making the difference in empowering the students with the needed skills, attitudes and competencies. This study explored the barriers to the use of ICTs in teaching and learning business education. The researcher constructed 15 questionnaire items from research reports relevant to the study. The questionnaire was validated using Cronbach Alpha which yielded a reliability coefficient of 0.78. A total of 256 questionnaire items were administered to 202 business educators and 54 students of business education respectively from Universities offering business education in Nigeria and all of which were completed and retrieved. The Research Question "what are the barriers to the use of ICTs in teaching and learning business education in Nigeria?" was answered using mean rating and standard deviation. The Hypothesis of no significant difference in the mean responses of business educators and business education students from universities regarding barriers to the use of ICTs in teaching and learning business education was tested using student $T$-test. The study revealed that all the constructs, except one, constituted barriers to the use of ICTs in teaching and learning business education in Nigeria universities. it was concluded that the revealed barriers be tackled by the government, the university authorities, the teachers and the students so that the university environment would be repositioned to play its role of empowering the youth with the skills, attitude and competencies needed for Nigeria's development.
\end{abstract}

Keywords: Information and Communication Technologies and Economic Development; Business Education and Economic Development

\section{INTRODUCTION}

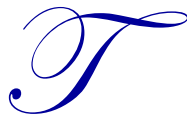

he Federal Government of Nigeria believes that business education as an instrument "per excellence" for national development. In pursuit of this lofty goal, government established universities as catalysts to bring about the desired change that will lead to the total transformation of the country's economy. It was rightly believed that the university environment is the most conducive for empowering the youth with skills and competencies needed to transform the individual and the society.

One of the programs in the universities believed to have the capacity to bring about the required development is business education. For this reason, the Federal Government of Nigeria (2006), through its policy on education, specified the objectives of business education to include: 
- $\quad$ To equip the business education graduates with the right skills that will enable them to engage in a life of work in the office as well as for self employment.

- To empower the individual with skills, knowledge and value to perform specific functions so as to become self reliant.

- $\quad$ To help him appreciate the world around him and contribute maximally to the social and economic development of his nation.

- $\quad$ To help the individual become a judicious spender and develop proper values for the growth of the nation.

- To empower the individual in such a way that he will develop his intellectual capacity that would help him to make informed decisions in all spheres of life.

According to Nannasy, Malsbury and Tonne (1997) Business education is that aspect of the total educational program that provides the knowledge, skills, understanding and aptitudes needed to perform in the business world as a producer or consumer of goods and services that business offers. Osuala (2004) added that it is a vocational education program leading to employability and advancement in office occupations and which provides students with information and competencies needed in managing personal business affairs and in using the services of the business world. It is very clear therefore, that business education is a course of instruction aimed at inculcating in the youth the skills, attitudes and competencies which are necessary to empower them to be gainfully engaged so that they will be useful citizens and contribute to the development of Nigeria and the society. As a field of study, business education provides skills in business practices covering accounting, marketing, office occupations and management.

Information and Communication Technology (ICT), according to Ikelegbe (2007) citing Frankie-Dolor (2004) consists of all the modern systems for processing information and communication in data, text, image and voice. He emphasized that ICT embraces all the technologies that support activities involving the creation of data, storage, manipulation and communication of information, including other methods, procedures, management and application. Osborne and Hennesey (2003) enumerated ICT tools for teaching and learning to include those for data capture, multimedia software for simulation, publishing and presentation tools, digital recording equipment, computer projection technology, and computer-controlled microscopes.

Since the early sixties when the first indigenous university was established by the Federal Government at Nsukka, to this day, with about 117 universities, gaps seem to persist between educational objectives and their realization. The glaring indicators of this state of affairs include poor skills of graduates who cannot fit into the office of today, unemployment, poverty, increase in crime and underdevelopment of the country. This unfortunate situation needs to be reversed especially now that the Federal Government is seriously seeking to transform all sectors of the economy. Since high levels of education are catalysts for rapid growth, it is imperative that the right kind of education should be provided to engender the expected change. After all, ICT should be the platform for any nation's growth and development in a rapidly changing and competitive world. In the meantime, traditional educational practice seem to have failed and can no longer provide teachers with current skills that today's workplace requires. As Igberaharha (2009) explained, education in Nigeria cannot be relevant without effective preparation of new generation students to effectively use the new ICTs in their professional practices. In realization of this handicap, UNESCO (2000) adopted a roadmap - Dakar Framework of Action for Education for all (EFA) in order to meet the education for all goals by 2015. However, UNESCO identified a key retardation factor as lack of ICT competencies on the part of teachers and suggested that "teachers must teach students to apply strategies for solving problems and to use appropriate tools for learning, collaborating, and communicating" (p. 1).

There is no doubt that ICTs have great potential for knowledge dissemination for both teachers and students. According to Rio-Cidoncha, Martinez-Palacios and Martinez-Lomas (2008), the use of ICTs in teachinglearning process allows the student as well as the teacher to overcome the time and space constraints which are present in traditional teaching. They maintained that "a world which is accessible from the web has been developed, which is very versatile as it works through a server which is connected to a local network" (p. 41). Furthermore, modern technology offers many means of improving teaching and learning in the classroom (Lefebvre, Deandeline \& Loiselle, 2006). In agreement with Lefebvre et al., Dawes (2001) earlier argued that new technologies have the potential to support education across the curriculum and provide opportunities for effective communication between teachers and students in ways that have not been possible before. Again Rio-Cidoncha et al. reported that ICTs 
offer a lot of advantages which can be applied to teaching business education: the possibility of creating communication multimedia environments, the ability to overcome the space-time limitations of attendance-based training, the facilitation of students being converted into information creators, the creation of an environment where information is conveyed non-prescriptively allowing the student to choose his/her own path according to what interests him/her, the creation of interactivity between system users, the immediate update of information and the preference to create collaborative environments for learning.

The importance of ICTs and the significant role it has to play in the future of education all over the world is no longer in doubt. However, this role may not easily be realized in view of separating or restraining obstacles termed 'barriers' inherent in the third-world countries like Nigeria. Even though barriers to the use of ICTs may have been studied, very few could be found that centered on Nigeria and particularly in the specific field of business education. Therefore, the purpose of this study was to identify barriers to the use of ICTs in teaching and learning business education in Nigeria universities.

\section{Research Question} universities?

What are the barriers to the use of ICTs in teaching and learning business education in Nigerian

\section{Research Hypothesis}

Lecturers and students do not differ significantly in their views regarding barriers to the use of ICTs in teaching and learning business education in Nigerian universities.

\section{METHODOLOGY}

Descriptive survey design was used in this study. A survey of lecturers and students in Nigerian universities offering business education was carried out to collect date regarding their opinions of what constitute barriers to the use of ICT in teaching and learning business education.

\section{Population of the Study}

The population of the study consisted of 253 business educators and 67 business education students who are registered members of the Association of Business Educators of Nigeria. All lecturers and students of business education who are not registered members were left out.

\section{Sampling Techniques}

Stratified random sampling technique was used by the researcher in selecting $80 \%$ each of the business educators and student members of the Association of Business Educators of Nigeria which yielded 202 and 54 respondents respectively.

\section{Instrument}

A questionnaire was used to gather data. It was constructed after review of literature related to the study. A reliability coefficient of 0.78 was obtained using Product Moment Coefficient. All items in the questionnaire were stated in a Likert format from Strongly Agree:5; Agree:4; Undecided:3; Disagree:2; and Strongly Disagree:1. The questionnaire contained a total of 15 items. A total of 256 questionnaire items were administered to the respondents during the National Conference of the Association of Business Educators of Nigeria held at the University of Lagos, Nigeria from $11^{\text {th }}$ to $15^{\text {th }}$ October, 2011. All the questionnaires were duly completed and retrieved with the help of eight colleagues. 


\section{Techniques for data analysis}

Data obtained were analyzed with means and standard deviation to answer the research question while the t-test statistics was employed to test the null hypothesis at 0.05 level of significance. A mean value of 3.50 and above indicated respondents' agreement with an item while a mean value of 3.49 and below indicated respondents' disagreement with an item. A calculated t-value that is equal or greater than the table value was considered significant and the null hypothesis rejected while a calculated $t$-value that is less than the table value was considered non-significant and the null hypothesis not rejected.

\section{Data analysis and Results}

The results in Table I show that all the items except item 16 have mean values well over 3.50 which is the stipulated positive decision rule. Eight items stand out with mean scores of well over 4.00. This indicated that corruption, poverty underfunding, lack of skill, teachers' confidence, lack of access to new technologies, poor maintenance culture and absence of critical infrastructure are in the forefront of the obstacles to the use of ICTs in the teaching and learning of business education courses. The only item rejected as an obstacle is the attitude about computers. The standard deviation scores between 0.38 and 1.47 indicated low variability in the opinion of the respondents.

Table 1: Respondents' views on barriers to the use of ICTs in teaching and learning business education

\begin{tabular}{|l|l|c|c|c|c|c|c|c|c|}
\hline S/NO & Items & SA & $\mathbf{A}$ & $\mathbf{U}$ & $\mathbf{D}$ & $\mathbf{S D}$ & $\mathbf{x}$ & $\boldsymbol{\sigma}$ & $\mathbf{D e c i s i o n}$ \\
\hline 1. & Corruption. & 112 & 81 & 60 & 3 & - & 4.17 & 0.83 & Agree \\
\hline 2. & Poverty. & 208 & 48 & - & - & - & 4.81 & 0.39 & Agree \\
\hline 3. & Underfunding. & 210 & 46 & - & - & - & 4.82 & 0.38 & Agree \\
\hline 4. & Lack of skills/competencies by teachers. & 98 & 92 & 51 & 9 & 6 & 4.04 & 0.97 & Agree \\
\hline 5. & Resistance to change. & 53 & 96 & 101 & 2 & 4 & 3.75 & 0.84 & Agree \\
\hline 6. & Lack of confidence by teachers. & 90 & 97 & 15 & 31 & 41 & 3.57 & 1.47 & Agree \\
\hline 7. & Lack of training. & 78 & 103 & 4 & 39 & 32 & 3.61 & 1.38 & Agree \\
\hline 8. & Poor prioritization of time. & 97 & 103 & - & 23 & 33 & 3.81 & 1.37 & Agree \\
\hline 9. & Lack of access to and used of new technologies. & 106 & 91 & 48 & 6 & 5 & 4.12 & 0.93 & Agree \\
\hline 10. & Poor technical support. & 111 & 70 & 24 & 49 & 2 & 3.93 & 1.17 & Agree \\
\hline 11. & Poor maintenance culture. & 151 & 69 & 29 & 7 & - & 4.42 & 0.93 & Agree \\
\hline 12. & Lack of motivation. & 129 & 113 & 4 & 6 & 4 & 4.39 & 1.17 & Agree \\
\hline 13. & Absence of critical infrastructure. & 123 & 130 & 3 & - & - & 4.47 & 0.52 & Agree \\
\hline 14. & Insufficient materials. & 117 & 139 & - & - & - & 3.91 & 0.99 & Agree \\
\hline 15. & Neglectful/dereliction of duty. & 52 & 112 & 60 & 32 & - & 3.77 & 0.93 & Agree \\
\hline 16. & Negative attitude about computer. & 82 & 30 & 80 & 12 & 3.32 & 1.24 & Disagree \\
\hline
\end{tabular}

Keys: SA - Strongly Agree; A - Agree; U - Undecided; D - Disagree; SD - Strongly Disagree.

The results in Table 2 show that the calculated $t$-value of 0.03 was less than the table $t$-value of 1.96. This indicated the acceptance of the null hypothesis of no significant difference between the mean opinion of lectures and students regarding barriers to the use of ICTs in teaching and learning business education.

Table 2: T-test result of lecturers and students regarding barriers to the use of ICTs in teaching and learning business education

\begin{tabular}{|l|c|c|c|c|c|c|c|c|}
\hline \multicolumn{1}{|c|}{ Groups } & Number & $\begin{array}{c}\text { Standard } \\
\text { deviation }\end{array}$ & Mean & $\begin{array}{c}\text { Degree Of } \\
\text { freedom }\end{array}$ & t-cal. & t-crit. & $\begin{array}{c}\text { Level Of } \\
\text { Sign. }\end{array}$ & Decision \\
\hline Lecturers & 202 & 0.43 & 4.02 & 254 & 0.03 & 1.96 & 0.05 & Accept \\
\hline Students & 54 & 0.44 & 4.07 & & & & & \\
\hline
\end{tabular}

\section{Discussion of the Findings}

The study was an attempt to determine the barriers to the use of ICTs in teaching and learning of business education courses in Nigerian universities. Corruption in Nigeria has reached an uncontrollable height and it would appear that all have agreed that the reason why Nigeria found it difficult to break through in several areas of development, particularly in technology, was, according to Achebe (1993) reported by Umoru (2006) simply and 
squarely the problem of endemic corruption and failure of leadership to rise to the responsibility and challenge of leadership and personal example. One of the findings was that poverty was a barrier to the use of new technologies in the nation's universities. Ile and Umezulike (2007) agreed that poverty causes one to see nothing good in another person's action and this impact negatively on the economic, social, intellectual and material well being of man. They explained further that the people find life unbearable as they are unable to provide for their basic needs of medical care, education and training. On lack of skills and competencies, the study found that it was the reason the use of new technologies was not fully embraced. This was supported by Ohakwe and Uba-Njoku (2010) who believed that the tertiary education teachers possess insufficient skills and competencies needed to utilize emerging ICTs and this was worsened by a weak ICTs backbone in the country, poor bandwidth provision and services in the educational sector. Teachers' lack of confidence was established by the study to be a reason for not using new technologies and this was explained by Balanskat et al. (2006) that limitations in teachers' ICTs knowledge makes them feel anxious about using ICT in the classroom and thus not confident to use it in their teaching. Resistance to change was found to be a strong barrier to the use of ICT in Nigeria. Even where new technologies are available, teachers were reluctant to use them and the reason advanced was that they were not motivated, guided or supported to enable them use the ICTs. Regarding lack of training, it was not a surprise that the study revealed it as a barrier because several issues relating to training such as time available, equipment, funding, pedagogy, skills, and ICTs use in teacher training, are complex enough for the effectiveness of the training to be achieved. While these limitations are still serious issues in Europe and Turkey particularly, (Ozden, 2007); Ohakwe and Uba-Njoku (2010) found that Nigeria is experiencing severe shortage of ICT skills, personnel, poor funding, poor backbone and out-of-date ICT infrastructure. This, very clearly explained the reason for lack of access to and use of new technologies which this study found was a serious barrier to teaching and learning business education in Nigerian universities. Pelgrum (2001) studied 26 countries to determine the obstacles to the implementation of ICT in schools and reported that four of the top ten barriers were related to accessibility of ICTs. These barriers were: insufficient numbers of computers, insufficient peripherals, insufficient numbers of copies of software, and insufficient simultaneous Internet access. In this current study, it was revealed too, that the situation has not changed in Nigeria. Lack of technical support and absence of maintenance culture were found by this study to be barriers to the use of ICTs in teaching and learning business education. Technical and maintenance support are very crucial to effective use of ICTs for teaching and learning. This was supported by Korte and Hüsing (2007) in their report that ICT support or maintenance contracts in schools help teachers to use ICT in teaching without losing time through having to fix software and hardware problems. Furthermore, Gomes (2005) agreed that lack of technical support was one of two significant barriers to the integration of ICT into science education in schools and might be considered serious. The only item rejected as a barrier was 'negative attitude about computer' and this may well be as a result of subjective perception usually attached to attitude and belief in the society.

\section{CONCLUSION}

The aim of this study was to ascertain the barriers to the use of ICTs in teaching and learning business education in Nigerian universities. The findings of this study indicated that teachers and students are denied the opportunity to use new technologies in the teaching and learning process as a result of the identified barriers. This implied that students of business education graduate from Nigerian universities without adequate knowledge, skill, attitude and competencies needed for survival in a globalized economy. It is a common belief that universities that do not embrace the use of new technologies, would certainly not be preparing their students for life in the twentyfirst century. Perhaps, the factors revealed by this study accounted for the depressed quality of the Nigerian educational system. No nation seriously striving for transformation of its economy can afford to ignore the training of its youth since a sound education is the main plank for national development. Therefore, the barriers revealed by this study should be addressed by government, the university authorities, the lecturers and the students so that the university environment would be repositioned to play its role in empowering the youth with the skills, attitude and competencies needed for Nigeria's development.

\section{AUTHOR INFORMATION}

Dr Titus A. Umoru is a lecturer of business education at the Kwara State University, Malete, Nigeria where he is the Coordinator of the Department of Business Education. His research areas include technology education and research, business teacher education knowledge and office occupation practices. He has published in Business 
Education Journals in Nigeria and African Journal of Teacher Education. His works have also been presented at international conferences on technology education, business teacher education and research. E-mail: umoruglo@yahoo.com

\section{REFERENCES}

1. Balanskat, A. Blamire, R. and Kefala, S. (2006). A Review of Studies of ICT Impact on Schools in Europe, European Schoolnet.

2. Dewis, L. (2001). "What Stops Teachers Using New Technology? "In M. Leask (Ed.), Issues in Teaching Using ICT, London: Routledge

3. Federal Government of Nigeria (2006). National Policy on Education, Lagos: NERDC.

4. Gomes, C. (2005). Integration of ICT in Science Teaching: A Study Performed in Azores, Portugal. Recent Research Development in Learning Technologies, 47(4), 47-61.

5. Igberaharha, O. C. (2009). "Issues of ICT in the teaching and learning of business education courses." Business Education Journal, 7(1), 95-105.

6. $\quad$ Ikelegbe, S. (2007). "Information and Communication Technologies.” Journal of Business Studies and Technology Development, 3(2), 129-136.

7. Ile, C. M. and Umezulike, A. N. (2007). "Poverty Reduction through business education: Evidence from medium scale entrepreneurs in Anambra State.” Business Education Journal. 4(1) 7-17.

8. Korte, W. B. and Hüsing, T. (2007). Benchmarking Access and use of ICT in European Schools 2006: Results From Head Teacher and Classroom Teacher Surveys in 27 European Countries. eLearning Papers, 2(1), 1-6.

9. Lefebvre, S., Deandeline, D., and Loiselle, J. (2006). ICT Implementation Stages of Primary School Teachers: The Practices and Conceptions of Teaching and Learning. Paper Presented at the Australian Association for Research in Education National Conference, Adeleide, Australia, November.

10. Nanassy, I. C., Malsbury, D. R. and Tonne, M. (1977). Principles and Trends in Business Education. Indianapolis: Bob Merril Educational Publishing.

11. Ohakwe, S. N. and Uba-Njoku, J. (2010). "ICT access to education and quality standards - Tripartite problems in Polytechnic education." Business Education Journal, 7(2) 239-249.

12. Osborne, J. and Hennessy, S. (2003). Literature review in science education and the role of ICT: Promise, problems and future directions. London: Futurelab.

13. Osuala, E. C. (2004). Foundations of Vocational Education, $\left(5^{\text {th }}\right.$ ed.), Calabar: Cheston Agency Limited.

14. Ozden, M. (2007). "Problems with science and technology education in Turkey. Eurasia Journal of Mathematics, Science and Technology Education, 3(2), 157-161.

15. Pelgrum, W. J. (2001). Obstacles to the integration of ICT in education: Results from worldwide educational assessment. Computers and Education, 37, 163-178.

16. Rio-Cidoncha, D., Martinez-Palacious, J. and Martinez-Lomas, E. (2008). "New Information and Communication Technologies for the teaching of computer graphic design," International Journal of Computer Science and Application, Vol. 5 (3a), 41-48.

17. UNESCO (2000). ICT Competencies for Teachers. Retrieved $12^{\text {th }}$ February, 2012 from file:///C:/Documents\%20Settings/user/My\%20Documents/ic...

18. Umoru, T. A. (2006). “Towards a new Nigeria." International Journal of Social and Policy Issues, 4, 5361. 